\title{
ROUTINE GYNAECOLOGICAL OPERATIONS WITHOUT BLOOD TRANSFUSION
}

\author{
MUSTAFA FN ${ }^{1}$, YASMIN N ${ }^{2}$, AFREEN N $^{3}$, HOSSAIN MN ${ }^{4}$, RAZIA SULTANA ${ }^{5}$
}

\begin{abstract}
:
Objective : To establish the fact that most of the routine gynaecological operations need no blood transfusion.

Method : This was a prospective observational study conducted in Dhaka Medical College Hospital from $15^{\text {th }}$ January, 2011 to $14^{\text {th }}$ April, 2011. Subjects were gynaecological patients admitted for routine operation. Main outcome variable was comparison of postoperative events between patients who received blood transfusion and who did not.
\end{abstract}

Results : 40 gynaecological patients were operated without blood transfusion (Group I) and 40 patients were taken who were operated with blood transfusion (GroupII). Among the patients $35 \%$ in Group I and $42.5 \%$ patients in Group II had some minor complications (hypotension, fever, wound infection and others) in postoperative period. The p value of of these postoperative complications in Group I is 0.020 and in Group II is 0.047 and $r=0.75$. The difference of $p$ value is significant. No patient of any group sufferred from any major comcplication.

Conclusion: There was no advantage of transfusing blood in routine gynaecological operation, rather more patients with blood transfusion had some minor postoperative complications.

Key words: Gynaecological Operations, Blood Transfusion.

J Dhaka Med Coll. 2018; 27(2) : 123-126

\section{Introduction}

Routine gynaecological operations are those surgical procedures where patients undergo schedule operation for gynaecological causes . General condition of these patients are usually stable.

Blood transfusion is the term used to describe the therapeutic use of whole blood and blood products. ${ }^{1,2}$ The study of Red Blood Cell (RBC) antigens and the antibodies reactive with them forms the foundation of transfusion medicine. ${ }^{1,2}$
Blood transfusion is a life saving procedure but it is not without risk. Receipients may rarely develop transfusion transmitted infection as well as suffer from immunological sequelae such as red cell alloimmunisation. A major risk of blood transfusion is the patient receiving mismatched blood. These emphasize the importance of knowledge about indication for blood transfusion and complication associated with it, as 2-5\% transfusion have been seen to be associated with adverse events. ${ }^{1}$ Sometimes we use blood over enthusiastically where blood transfusion could be avoided.

\section{Blood transfusion is indicated in the following cases 3 :}

\begin{tabular}{ll}
\hline Clinical condition & Transfusion trigger \\
\hline Acute anaemia & $\mathrm{Hb}<-8 \mathrm{gm} / \mathrm{dl}$ or presence of symptom \\
Surgical hemorrhage---------- & $\mathrm{Hemorrhagic} \mathrm{shock}$ \\
Traumatic hemorrhage ------ & $\mathrm{Hb}<7 \mathrm{gm} / \mathrm{dl}$ or presence of symptom \\
Non-surgical/ Non-traumatic Hemorrhage--- & $\mathrm{Hb}<7 \mathrm{gm} / \mathrm{dl}$ or presence of symptom \\
Critical illness------------------ & $\mathrm{Hb}<9 \mathrm{gm} / \mathrm{dl}$ (weak evidence) \\
Early sepsis with inadequate oxygen supply-- & $\mathrm{Hb}<7 \mathrm{gm} / \mathrm{dl}$ \\
Septic shock, Late sepsis ------- & $\mathrm{Hb}<9 \mathrm{gm} / \mathrm{dl}$ (weak evidence) \\
Acute coronary syndrome------ & No clear cut transfusion triggers have been \\
Chronic anaemia & defined. Decision to transfuse is individualized \\
Chronic blood loss & based on symptoms and functional impairment. \\
Decreased erythropoiesis &
\end{tabular}

1. Dr. Fahmida Naz Mustafa, Assistant Professor, Obs and Gynae Deptt, Mugda Medical College, Dhaka.

2. Prof. Nahid Yasmin, Head, Department of Obs nad Gynae, Mugda Medical College

3. Dr. Nasreen Afreen, Assistant Professor, Mugda Medical College

4. Dr. Md. Nabir Hossain, Associate Professor, Department of Surgical Oncology, National Institute of Cancer Research and Hospital , Dhaka

5. Dr. Razia Sultana, Assistant Professor, Department of Community Medicine, DMC, Dhaka

Correspondence : Dr. Fahmida Naz Mustafa, Assistant Professor, Obs and Gynae Deptt, Mugda Medical College, Mugda, Dhaka. Email : nazf04@yahoo,com Mobile : 01715038881 
In obstetric and gynaecological patients very often blood is transfused. In some patients, especially in emergency obstetric patients, transfusion is needed. But in routine gynaecological operative cases, the contrary is true. Here less often transfusion is needed. But unfortunately, we often injudiciously and unnecessarily transfuse blood, which has risk of blood reaction and transmitting blood transmitted diseases.

\section{A safe blood supply depends on :}

1. A well-organized supply system that ensures regular donation by healthy individuals who have no excessive risk of transmissible infection.

2. Testing of all donated blood to exclude HIV, Hepatitis B, Hepatitis C, Syphilis and other infectious agents .

3. Effective control over the quality of testing techniques, eg, blood grouping, storage and screening for infectious agents.

Unfortunately, in our country, a large portion of blood is supplied by professional donors, who donate in exchange of money. And in many small diagnostic centres screening procedures are not adequate. Private blood banks are seen nearby all hospitals. These blood banks are formed with commercial motive without proper screening and storage system. They take blood from professional donors in exchange of money and sell it to the patients for money. Many of the professional donors are addict and they have the chance of carrying various infectious agents. In transmitting HIV the efficiency of transmission through blood transmission is alarming. While efficiency of transmission per single sexual exposure is $1 \%$, it is through blood transfusion is $90 \%$. In $2002,5-10 \%$ of newly acquired HIV infections were related to infected blood transfusions. ${ }^{4}$

Now it has come time to give a look into the reality that is it always necessary or judicious to transfuse blood so often to our routine gynaecological operative patients?

\section{Objectives of the study:}

This study was carried out to establish the fact that most of the routine gynaecological operations need no blood transfusion.

\section{Inclusion Criteria:}

- Routine gynaecological operations.

- Haemoglobin level $55-65 \%$.

\section{Exclusion Criteria:}

- No emergency gynaecological cases were included.

- Severe anemia patients were excluded.

\section{Methodology}

The place of study was Dhaka Medical College Hospital and duration was from $15^{\text {th }}$ January, 2011 to $14^{\text {th }}$ April, 2011.

We have carried out a prospective observational and analytical study on 80 patients. These were routine gynaecological cases where major operative procedures were performed. Majority of the patients' preoperative $\mathrm{Hb} \%$ was between 55 to $65 \%$. Among the 80 patients, 40 patients did not have blood transfusion and 40 patients had blood transfusion. $\mathrm{Hb} \%$ was done again postoperatively in all patients. We followed up the postoperative period and documented our findings.

\section{Result :}

In both Group I (Without blood transfusion) and Group II (With blood transfusion) age of the patients range from 36 to $60 \mathrm{yrs}$ and there is no significant difference between the two groups. Majority of the patients come from lower socioeconomic condition in both groups. Total abdominal hysterectomy was done in 32 patients in each group for fibroid uterus and Dysfunctional uterine bleeding. Vaginal hysterectomy was done for genital prolapse in 08 patients in each group. In all patients Preoperative $\mathrm{Hb} \%$ was $55 \mathrm{gm} \%$ or more. Postoperative $\mathrm{Hb} \%$ was also $55 \mathrm{gm} \%$ or more in all patients. Hospital stay was almost same in both groups. General condition was good in all patients on discharged.

Only difference between the two groups was that in postoperative period, some minor complications like hypotension, fever, wound infection and others occurred in both groups in significant difference. The $\mathrm{p}$ value of postoperative complication in Group I is 0.020 and in Group II is 0.047 and $r=0.75$. So the difference of $p$ value is significant. It means the 
difference between the incidence of postoperative complication is significant. In our study we have seen that there is no advantage of blood transfusion over not transfusing, rather there is more incidence of fever in the blood transfused patients. So we should and must avoid blood transfusion in routine gynaecological operations, where blood transfusion is not absolutely needed.

Table I

Age Distribution

\begin{tabular}{lcc}
\hline Age & Group I & Group II \\
\hline $36-45$ yrs & 19 & 17 \\
$46-50$ yrs & 9 & 8 \\
$51-60$ yrs & 12 & 15 \\
\hline
\end{tabular}

Table II

Socioeconomic Status

\begin{tabular}{lcc}
\hline $\begin{array}{l}\text { Socioeconomic } \\
\text { condition }\end{array}$ & Group I & Group II \\
\hline Lower & 26 & 27 \\
Middle & 11 & 9 \\
Higher & 03 & 4 \\
\hline
\end{tabular}

Table III

Diseases of Patients

\begin{tabular}{lcc}
\hline Name of Disease & Group I & Group II \\
\hline Fibroid & 17 & 18 \\
DUB & 15 & 14 \\
Genital Prolapse & 08 & 08 \\
\hline
\end{tabular}

Table IV

Preoperative $\mathrm{Hb} \%$

\begin{tabular}{lcc}
\hline Preoperative Hb\% & Group I & Group II \\
\hline $55-60$ gm $\%$ & 22 & 20 \\
$61-70 \mathrm{gm} \%$ & 12 & 12 \\
$>70 \mathrm{gm} \%$ & 06 & 08 \\
\hline
\end{tabular}

Table V

Postoperative $\mathrm{Hb} \%$

\begin{tabular}{lcc}
\hline Postoperative Hb\% & Group I & Gorup II \\
\hline 55-60gm\% & 20 & 17 \\
61-70gm\% & 17 & 19 \\
$>70 \mathrm{gm} \%$ & 03 & 04 \\
\hline
\end{tabular}

Table VI

Hospital Stay

\begin{tabular}{lcc}
\hline Hospital Stay & Group I & Group II \\
\hline 5-7days & 33 & 32 \\
8-10 days & 04 & 05 \\
11-14 days & 03 & 03 \\
\hline
\end{tabular}

Table VII

General condition on discharge :

\begin{tabular}{lcc}
\hline General condition & Group I & Group II \\
\hline Good & 40 & 40 \\
Bad & 0 & 0 \\
\hline
\end{tabular}

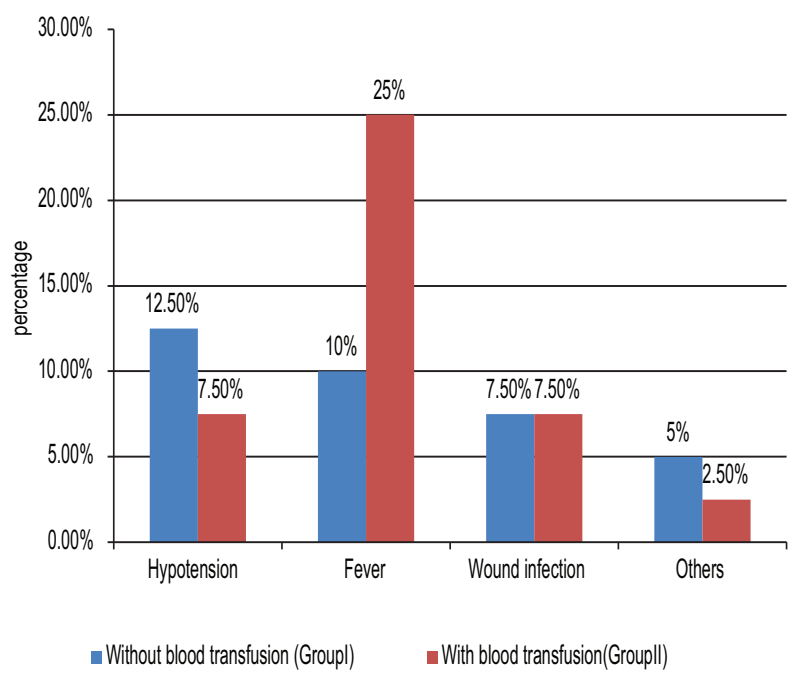

Fig.-I : Comparison of postoperative findings of Group I and Group-II 
Table VIII

Comparison of postoperative findings of Group I and Group-II

\begin{tabular}{lcccccc}
\hline & \multicolumn{2}{c}{ Number } & \multicolumn{2}{c}{ Percentage } & \multicolumn{2}{c}{ P value } \\
& Group I & Group II & Group I & Group II & Group I & Group II \\
\hline Hypotension & 5 & 3 & 12.5 & 7.5 & 0.020 & 0.047 \\
Fever & 4 & 10 & 10.0 & 25.0 & & \\
Wound Infection & 3 & 3 & 7.5 & 7.5 & & \\
Others & 2 & 1 & 5.0 & 2.5 & & \\
Total & 14 & 17 & 35 & 42.50 & & \\
\hline
\end{tabular}

\section{Discussion:}

There is considerable uncertainty regarding the optimal haemoglobin threshold for the use of red blood cell (RBC) transfusions in anaemic patients. Blood is a scarce resource, and in some countries, transfusions are less safe than others because of a lack of testing for viral pathogens. Therefore, reducing the number and volume of transfusions would benefit patients. ${ }^{5}$

A review study was done by Carson $\mathrm{JL}$ et al of New Jersy with the title, "Transfusion thresholds and other strategies for guiding allogeneic red blood cell transfusion." A total of 31 trials, involving 12,587 participants, across a range of clinical specialities (e.g. surgery, critical care) were studied. They defined participants randomly and allocated to the lower blood transfusion threshold as 'restrictive transfusion' and to the higher transfusion threshold as 'liberal transfusion'. Blood transfusion threshold was $7 \mathrm{~g} / \mathrm{dL}$ in about half of the participants in restrictive transfusion group, and the other half used transfusion threshold of $8 \mathrm{~g} / \mathrm{dL}$ to $9 \mathrm{~g} / \mathrm{dL}$ in liberal transfusion group. The study showed that restrictive transfusion strategies did not increase or decrease the risk of 30-day mortality compared with liberal transfusion strategies or any of the other outcomes assessed, i.e. cardiac events, myocardial infarction, stroke, thromboembolism . Liberal transfusion also did not affect the risk of infection (pneumonia, wound, or bacteraemia). The author's conclusion was that transfusing at a restrictive haemoglobin concentration of $7 \mathrm{~g} / \mathrm{dL}$ decreased the proportion of participants exposed to RBC transfusion by $43 \%$ across a broad range of clinical specialities. The findings provide good evidence that transfusions with allogeneic RBCs can be avoided in most patients with haemoglobin thresholds above $7 \mathrm{~g} / \mathrm{dL}$.

In a study, entitled 'Indications and hazards of emergency whole blood transfusion in obstetric practice $^{6}$, done in Dhaka Medical College Hospital in 2013, it was seen that among all transfusions, transfusion hazards developed in $11.84 \%$ cases, of them $7.48 \%$ were allergic reaction, $3.16 \%$ febrile reaction and $1.05 \%$ circulatory overload. In another study, entitled 'Evaluation, outcome and strategy of safe blood transfusion in obstetric hemorrhage' 7 , done in 2012 - 2013 period, almost same findings were found with transfusion hazards in $11.81 \%$ cases.

\section{Conclusion:}

Analysing the result of our study and also discussing other studies done in our country and abroad, we find that there is no advantage of transfusing blood in routine gynaecological operations, rather a significant number of patients with blood transfusion have some minor postoperative complications.

\section{References:}

1. Fuller AJ, Bucklin B. Blood Component therapy in obstetrics. Obstet Gynaecol Clin N Am 2007; 34: 443458

2. Wriglit PA: Donor selection and component preparation, Harmening DM $3^{\text {th }}$ ed. Modern Blood Banking and transfusion practices New Delhi, India , laypee Hmthcrs 1998; 19x-232

3. Indications for blood and blood product transfusion. Yaddanapudi S, Yaddanapudi L. Indian J Anaesth. 2014 Sep;58(5):538-42. doi: 10.4103/0019-5049. 144648. Review.

4. Interim Report on the Confidential Enquiry into Maternal Deaths in South Africa. March 1998.htm.

5. Carson JL, et al. Cochrane Database Syst Rev. 2016 Oct 12;10:CD002042.

6. Dr. Arifa Sultana, Indications and hazards of emergency whole blood transfusion in obstetric practice, a dissertation submitted in Bangladesh College of Physician and Surgeons, Dhaka, Bangladesh in 2014 .

7. Dr. Nazia Sharmin, Evaluation, outcome and strategy of safe blood transfusion in obstetric hemorrhage, a dissertation submitted in Bangladesh College of Physician and Surgeons, Dhaka, Bangladesh in July,2014. 